\title{
Characterization of phenolic compounds in flowers of wild medicinal plants from
}

\section{Northeastern Portugal}

Lillian Barros $^{1,2, \mathrm{a}}$, Montserrat Dueñas ${ }^{2, \mathrm{a}}$, Ana Maria Carvalho ${ }^{1}$, Isabel C.F.R. Ferreira ${ }^{1, *}$, Celestino Santos-Buelga ${ }^{2, *}$

${ }^{\text {a }}$ Both authors contributed equally

${ }^{1} \mathrm{CIMO} /$ Escola Superior Agrária, Instituto Politécnico de Bragança, Campus de Santa Apolónia, Apartado 1172, 5301-855 Bragança, Portugal.

${ }^{2}$ Grupo de Investigación en Polifenoles (GIP-USAL), Facultad de Farmacia, Universidad de Salamanca, Campus Miguel de Unamuno, 37007 Salamanca, Spain.

Authors to whom correspondence should be addressed (e-mail: iferreira@ipb.pt, telephone +351273303219 , fax +351273325405 ; e-mail: csb@usal.es; telephone +34 923 294537; fax +34 923 294515). 


\begin{abstract}
Crataegus monogyna, Cytisus multiflorus, Malva sylvestris and Sambucus nigra have been used as important medicinal plants in the Iberian Peninsula since a long time ago, and are claimed to have various health benefits. This study aimed to determine the phenolic profile and composition of wild medicinal flowers of those species. The analysis was performed by HPLC-DAD-ESI/MS. Flavonoids, and particularly flavonols and flavones, were the main groups in almost all the studied samples. C. multiflorus sample gave the highest levels of total flavonoids $(54.5 \mathrm{mg} / \mathrm{g} \mathrm{dw})$, being a chrysin derivative the most abundant flavone found $(22.3 \mathrm{mg} / \mathrm{g} \mathrm{dw})$. C. monogyna revealed the highest concentration in phenolic acids $(5.5 \mathrm{mg} / \mathrm{g} \mathrm{dw})$ that were not found in $C$. multiflorus sample; 5-O-caffeoylquinic acid was the most abundant phenolic acid found in the first species, being a procyanidin trimer also found $(1.4 \mathrm{mg} / \mathrm{g} \mathrm{dw})$. Kaempferol-3$O$-rutinoside $(0.84 \mathrm{mg} / \mathrm{g} \mathrm{dw})$ and quercetin-3-O-rutinoside $(14.9 \mathrm{mg} / \mathrm{g} \mathrm{dw})$ were the main flavonols present in $M$. sylvestris and $S$. nigra, respectively. Due to the well established antioxidant activity of phenolic compounds, the studied wild medicinal flowers could be selected for processing extracts with health-promoting properties or to be incorporate into functional beverages or products with bioactive properties related to oxidative stress.
\end{abstract}

Keywords: MAP; Wild flowers; flavonoids; HPLC-DAD-ESI/MS. 


\section{Introduction}

Reactive oxygen and nitrogen species (ROS and RNS) such as superoxide anion $\left(\mathrm{O}_{2}{ }^{--}\right)$, hydroxyl radical $\left(\mathrm{OH}^{\circ}\right)$, hydrogen peroxide $\left(\mathrm{H}_{2} \mathrm{O}_{2}\right)$, nitric oxide $\left(\mathrm{NO}^{\circ}\right)$ and peroxynitrite anion $\left(\mathrm{ONOO}^{-}\right)$are highly reactive species that are responsible for many cell disorders through their action on proteins, DNA, and lipid peroxidation. By modifying the oxidative balance within the cells, these ROS and RNS are important mediators of cell injuries. They are assumed to play an important role in the development of many diseases such as atherosclerosis, reperfusion injury, cataractogenesis, rheumatoid arthritis, neurodegenerative and inflammatory disorders, cardiovascular disease and cancer, besides being involved in the aging process itself (Halliwell and Gutteridge, 1999; Ghafourifar and Cadenas, 2005; Valko et al., 2007).

In the last years epidemiological studies have shown an inverse correlation between increased consumption of antioxidants such as polyphenols and risk of some of the mentioned disorders induced by oxidative stress (López-Lázaro, 2002; Youdim et al., 2002; Steinberg et al., 2003; He et al., 2006). However, information about their bioactive forms in vivo and the mechanisms by which they may contribute toward disease prevention is still necessary. Therefore, absorption, distribution, metabolism or excretion, or the plasma/tissue levels of the metabolites of phenolic compounds that might occur, should be considered on studies of their biological (Rechner et al., 2002). Polyphenols are widely distributed and can exist as simple phenolic acids and flavonoids, or as complex molecules with numerous phenolic groups, e.g. acylated flavonoid glycosides, proanthocyanidins or oligomeric hydrolysable tannins (Fecka, 2009). The positive effects of polyphenols in relation to cardiovascular diseases are probably associated with their ability to increase the antioxidative capacity of the blood plasma and prevent oxidation of low density lipoprotein (LDL) and platelet aggregation. 
Their potential cancer preventive effects may be due to their ability to modulate enzyme activities resulting in decreased carcinogenicity of xenobiotics and preventing the development of oxidative stress induced cancer. Finally, polyphenols may also provide anti-inflammatory properties (Kaack and Christensen, 2010). Overall, these substances have the capacity for acting as potent radical scavengers, inhibiting a variety of enzymes, and have also an antihemorrhagic activity by tightening blood vessels (Dawidowicz et al., 2003).

Recently, there has been an increased interest in wild plants rich in phenolic compounds due to their possible beneficial effects on human health. Moreover, some flowers from wild species such as Crataegus monogyna, Cytisus multiflorus, Malva sylvestris and Sambucus nigra have been traditionally used for several medicinal applications (Table 1). Our research group has already reported their powerful antioxidant properties (Barros et al., 2010; Barros et al., 2011a; Barros et al., 2011b), that are certainly related to their composition in phenolic compounds.

In this study we performed an exhaustive characterization of phenolic compounds present in those medicinal flowers. There are available studies in literature that described phenolic composition in M. sylvestris leaves (Nawwar and Buddrust, 1981; Billeter et al., 1991), but not in its flowers. Regarding C. multiflorus, there is a recent report on the phenolic composition of non-wild samples (Pereira et al., 2012). C. monogyna (Froehlicher et al., 2009) and S. nigra (Dawidowicz et al., 2003; Rieger et al., 2008; Christensen et al., 2008; Kaack and Christensen, 2010) flowers were studied, but with plant material from other European countries, i.e not growing under Mediterranean particular climatic and soil conditions.

\section{Materials and methods}




\subsection{Samples}

All plant materials (the parts most cited for medicinal use by key informants during ethnobotanical surveys) were collected in early and late spring of 2009 (depending on each species phenology), in the Natural Park of Montesinho territory, Trás-os-Montes, North-eastern Portugal, considering the Portuguese folk pharmacopoeia, local medicinal criteria of use and each plant growth pattern. Crataegus monogyna, the flowers during anthesis plus few expanded leaves attached at the base of the inflorescence peduncle; Cytisus multiflorus and Sambucus nigra, the inflorescences with flowers fully open and functional; Malva sylvestris the flowers' buds and flowers on the upper stems.

Morphological key characters from the Flora Ibérica (Castroviejo 2001, 2005 and 2007) were used for plant identification. Voucher specimens are kept at the Herbário da Escola Superior Agrária de Bragança (BRESA). Each sample was lyophilized (Ly-8-FM-ULE, Snijders, Holland) and stored in the deep-freezer at $-20^{\circ} \mathrm{C}$ for subsequent analysis.

\subsection{Standards and reagents}

HPLC-grade acetonitrile was obtained from Merck KgaA (Darmstadt, Germany). Formic acid was purchased from Prolabo (VWR International, France). The phenolic compounds standards (apigenin-6- $C$-glucoside, catechin, chrysin, caffeic acid, chlorogenic acid (5-O-caffeoylquinic acid), gallic acid, isorhamnetin, isorhamnetin-3-Oglucoside, kaempferol-3-O-glucoside, kaempferol-3-O-rutinoside, luteolin-6-Cglucoside, quercetin-3-O-glucoside, quercetin-3-O-rutinoside) were from Extrasynthese (Genay, France). All other chemicals were of analytical grade and purchased from chemical suppliers. Water was treated in a Milli-Q water purification system (TGI Pure Water Systems, USA). 


\subsection{Phenolic compounds extraction}

Each sample $(1 \mathrm{~g})$ was extracted with $30 \mathrm{~mL}$ of methanol:water 80:20 (v:v) at room temperature, $150 \mathrm{rpm}$, for $1 \mathrm{~h}$. The extract was filtered through Whatman $\mathrm{n}^{\mathrm{o}} 4$ paper. The residue was then re-extracted twice with additional $30 \mathrm{~mL}$ portions of methanol:water 80:20 (v:v). The combined extracts were evaporated at $35^{\circ} \mathrm{C}$ (rotary evaporator Büchi R-210) to remove methanol. The aqueous phase was lyophilized and re-dissolved in $20 \%$ aqueous methanol at $5 \mathrm{mg} / \mathrm{mL}$ and filtered through a $0.22-\mu \mathrm{m}$ disposable LC filter disk for High Performance Liquid Chromatography (HPLC) analysis.

C. monogyna sample and standards 5-O-caffeolyquinic acid, $p$-coumaric acid and caffeic acid were also analysed after submitting it to UV irradiation at $366 \mathrm{~nm}$ for $24 \mathrm{~h}$ so as to check inter-conversion between trans and cis isomers.

2.4. HPLC-DAD-ESI/MS analyses for phenolic compounds identification and quantification

The extracts were analysed using a Hewlett-Packard 1100 chromatograph (Agilent Technologies) with a quaternary pump and a diode array detector (DAD) coupled to an HP Chem Station (rev. A.05.04) data-processing station. A Waters Spherisorb S3 ODS$2 \mathrm{C} 18,3 \mu \mathrm{m}(4.6 \mathrm{~mm} \times 150 \mathrm{~mm})$ column thermostatted at $35^{\circ} \mathrm{C}$ was used. The solvents used were: (A) $0.1 \%$ formic acid in water, (B) acetonitrile. The elution gradient established was $10 \% \mathrm{~B}$ to $15 \% \mathrm{~B}$ over $5 \mathrm{~min}, 15-25 \% \mathrm{~B}$ over $5 \mathrm{~min}, 25-35 \% \mathrm{~B}$ over $10 \mathrm{~min}$, isocratic $50 \% \mathrm{~B}$ for $10 \mathrm{~min}$, and re-equilibration of the column, using a flow rate of $0.5 \mathrm{ml} / \mathrm{min}$. Double online detection was carried out in the DAD using $280 \mathrm{~nm}$ and $370 \mathrm{~nm}$ as preferred wavelengths and in a mass spectrometer (MS) connected to HPLC system via the DAD cell outlet. 
MS detection was performed in an API 3200 Qtrap (Applied Biosystems, Darmstadt, Germany) equipped with an ESI source and a triple quadrupole-ion trap mass analyzer that was controlled by the Analyst 5.1 software. Zero grade air served as the nebulizer gas (30 psi) and turbo gas for solvent drying (400 ${ }^{\circ} \mathrm{C}, 40 \mathrm{psi}$ ). Nitrogen served as the curtain (20 psi) and collision gas (medium). The quadrupols were set at unit resolution. The ion spray voltage was set at $-4500 \mathrm{~V}$ in the negative mode. The MS detector was programmed for recording in two consecutive modes: Enhanced MS (EMS) and enhanced product ion (EPI) analysis. EMS was employed to show full scan spectra, so as to obtain an overview of all of the ions in sample. Settings used were: declustering potential (DP) $-450 \mathrm{~V}$, entrance potential (EP) $-6 \mathrm{~V}$, collision energy (CE) -10V. EPI mode was performed in order to obtain the fragmentation pattern of the parent ion(s) in the previous scan using the following parameters: DP $-50 \mathrm{~V}, \mathrm{EP}-6 \mathrm{~V}, \mathrm{CE}-25 \mathrm{~V}$, and collision energy spread (CES) $0 \mathrm{~V}$. Spectra were recorded in negative ion mode between $\mathrm{m} / \mathrm{z} 100$ and 1000.

The phenolic compounds present in the samples were characterised according to their UV and mass spectra and retention times compared with commercial standards when available. For the quantitative analysis of phenolic compounds, a calibration curve was obtained by injection of known concentrations $(2.5-100 \mu \mathrm{g} / \mathrm{mL})$ of different standards compounds: $\quad$ apigenin-6- $C$-glucoside $\quad\left(\mathrm{y}=246.05 \mathrm{x}-309.66 ; \quad \mathrm{R}^{2}=0.9994\right) ; \quad$ catechin $\left(y=132.76 x-59.658 ; R^{2}=0.9997\right) ;$ chrysin $\left(y=43.957 x-620.02 ; R^{2}=0.9988\right)$; caffeic acid $\left(y=617.91 x-691.51 ; R^{2}=0.9991\right) ;$ chlorogenic acid $\left(y=600.27 x-763.62 ; R^{2}=0.9998\right) ;$ gallic acid $\quad\left(y=556.94 x-738.37 ; \quad R^{2}=0.9988\right) ; \quad$ isorhamnetin $\quad(y=629.14 x-2323.4$; $\left.\mathrm{R}^{2}=0.9967\right)$; isorhamnetin-3-O-glucoside $\left(\mathrm{y}=262.31 \mathrm{x}-9.8958 ; \mathrm{R}^{2}=1.000\right)$; kaempferol3-O-glucoside ( $\left.\mathrm{y}=190.75 \mathrm{x}-36.158 ; \mathrm{R}^{2}=1.000\right)$; kaempferol-3- $O$-rutinoside $(\mathrm{y}=175.02 \mathrm{x}-$ 43.877; $\left.\mathrm{R}^{2}=0.9999\right)$; luteolin-6- $C$-glucoside $\left(\mathrm{y}=365.93 \mathrm{x}-17.836 ; \mathrm{R}^{2}=0.9997\right)$; quercetin- 
3-O-glucoside $\left(\mathrm{y}=316.48 \mathrm{x}-2.9142 ; \mathrm{R}^{2}=1.000\right)$; quercetin-3- $O$-rutinoside $(\mathrm{y}=222.79 \mathrm{x}-$ 243.11; $\left.\mathrm{R}^{2}=0.9998\right)$. The results were expressed in $\mathrm{mg}$ per $\mathrm{g}$ of dry weight $(\mathrm{dw})$, as mean \pm standard deviation of three independent analyses.

\section{Results}

\subsection{Quantification of the identified phenolic compounds}

Figure 1 shows the profiles of different classes of phenolic compounds determined in C. monogyna, C. multiflorus, M. sylvestris and S. nigra flowers, which include phenolic acids and flavonoids (flavonols, flavones and procyanidins). Flavonoids, and particularly flavonols and flavones, were the main groups in almost all the studied samples. C. multiflorus sample gave the highest levels of total flavonoids $(54.5 \mathrm{mg} / \mathrm{g}$ $\mathrm{dw}$ ), being flavones $(41.5 \mathrm{mg} / \mathrm{g} \mathrm{dw})$ the main compounds found, and therefore the highest levels of total phenolic compounds (Figure 1). S. nigrans presented the highest levels of flavonols $(20.5 \mathrm{mg} / \mathrm{g} \mathrm{dw})$; otherwise C. monogyna presented the highest concentration in phenolic acids $(5.5 \mathrm{mg} / \mathrm{g} \mathrm{dw})$, which were not found in C. multiflorus sample, whereas procyanidins $(1.4 \mathrm{mg} / \mathrm{g} \mathrm{dw})$ were only found in minor levels in $C$. monogyna (Figure 1). As an example, the HPLC phenolic profiles of C. monogyna flowers recorded at $280 \mathrm{~nm}$ and $370 \mathrm{~nm}$ can be observed in Figure 2.

Table 2 presents the data obtained from HPLC-DAD-MS analysis (retention time, $\lambda_{\max }$ in the visible region, mass spectral data) used for the identification and quantification of phenolic compounds in the four medicinal flowers.

\subsection{Phenolic acids and derivatives}

Phenolic acids and derivatives were found in all the medicinal flowers with exception of C. multiflorus, which did not present these compounds. Diverse hydroxycinnamic acid 
derivatives were found in C. monogyna, M. sylvestris and S. nigra samples. Chlorogenic acids are a family of esters formed between certain trans cinnamic acids, most commonly caffeic, $p$-coumaric and ferulic and quinic acid (IUPAC, 1976, Clifford et al., 2003, 2005, 2006, 2007). Using a more general definition, all esters of quinic acids and their diastereomers can be considered as chlorogenic acids. In the IUPAC system, ()-quinic acid is defined as 11-1(OH),3,4/5-tetrahydroxycyclohexane carboxylic acid (IUPAC, 1976), but Eliel and Ramirez (1997) propose $1 \alpha, 3 \mathrm{R}, 4 \alpha, 5 \mathrm{R}-$ tetrahydroxycyclohexane carboxylic acid. The detected compounds showed UV spectra with a $\lambda_{\max }$ at 312,326 and $330 \mathrm{~nm}$ and pseudo molecular ions $[\mathrm{M}-\mathrm{H}]^{-}$at $\mathrm{m} / \mathrm{z} 353 \mathrm{or} \mathrm{m} / \mathrm{z}$ 337, all of them yielding a product ion at $\mathrm{m} / \mathrm{z} 191$, due to the deprotonated quinic acid, so that they could be clearly identified as quinic acid derivatives containing one caffeic acid or $p$-coumaric acid moiety, respectively (Table 2). Free caffeic acid was only found in M. sylvestris and was identified by comparison of its UV spectrum and retention time with a commercial standard.

Peak assignments of the different caffeoylquinic acid isomers found in the extracts from C. monogyna and S. nigra were made using the recommended IUPAC numbering system (IUPAC,1976) as also the hierarchical keys previously developed by Clifford et al. (2003, 2005), and specimen structures are presented in Figure 3. According to Clifford et al. (2003, 2005, 2006, 2007; Lin and Harnly, 2008), many plants produce different caffeoylquinic acids in which esterification occurs at positions 3, 4 and 5 of the quinic acid moiety.

Peaks 4 and 3 in C. monogyma and S. nigra, respectively, were positively identified 5$O$-caffeoylquinic acid by comparison with an authentic standard. Peak 2 in $C$. monogyna, identified as 3-O-caffeoylquinic acid, yielded the base peak at $\mathrm{m} / \mathrm{z} 191$ (deprotonated quinic acid) and also gave an ion at $\mathrm{m} / z 179$ [caffeic acid-H]', with an 
intensity $>50 \%$ base peak. Similar fragmentation pattern was already reported by Clifford, et al. $(2003,2005)$ and used to distinguish 3-acylchlorogenic acids.

Peak 1 in C. monogyna and S. nigra showed similar fragmentation pattern and fragment abundances as those obtained for 3-O-caffeoylquinic acid, pointing out to they could be the corresponding cis isomer. With the aim of obtaining further support to this assumption, the Crataegus sample was UV-irradiated so as to try and induce the partial conversion of the trans isomer to the corresponding $\mathrm{cis}$ isomer. However, no relevant decrease in the size of peak 2 was observed nor an increase in the size of peak 1, which indeed did not support the cis nature of peak 1. Furthermore, commercial standards of chlorogenic acid (i.e., trans 5-O-caffeoylquinic acid), (trans) caffeic acid and (trans) $p$ coumaric acid were also submitted to UV irradiation in the same conditions as used for the Crataegus sample (i.e., $366 \mathrm{~nm}, 24 \mathrm{~h}$ ). Only partial transformation of $p$-coumaric acid with appearance of a new peak at earlier retention time in the HPLC chromatogram, attributed to the corresponding cis isomer was found, whereas no changes were observed in the chromatograms obtained after irradiation of the chlorogenic and caffeic acids. In these circumstances, it might be assumed that the UV irradiation conditions used were sufficient for the transformation of the $p$-coumaric acid but not the caffeic acid moiety to the corresponding cis isomer. Therefore, it might be possible that conversion from peak 2 to 1 following irradiation was not produced or occurred in a small extent, insufficient to produce a sizeable modification in the peak areas. All in all, although the actual identity of peak 1 remains unclear, based on its fragmentation pattern and small levels it was tentatively assigned as cis-3-Ocaffeoylquinic acid.

Peak 3 in C. monogyna was easily distinguished from the other two isomers by its base peak at $m / z 173$ [quinic acid- $\left.-\mathrm{H}_{2} \mathrm{O}\right]^{-}$, accompanied by a secondary fragment ion at $\mathrm{m} / \mathrm{z}$ 
179 with approximately $70 \%$ abundance of base peak, which allowed identifying as 4$O$-caffeoylquinic acid according to the fragmentation pattern described by Clifford et al. (2003, 2005). A signal at $m / z 515$ was observed in C. monogyna (peak 15) and S. nigra (peak 11), which would correspond to a dicaffeoylquinic acid and was tentatively assigned as 3,5-O-dicaffeoylquinic acid based on its fragmentation pattern and abundances described by Clifford et al. (2005). $\mathrm{MS}^{2}$ base peak was at $m / z 353$, produced to the loss of one of the caffeoyl moieties [M-H-caffeoyl]', and subsequent fragmentation of this ion yielded the same fragments as a 5-O-caffeoylquinic acid at $\mathrm{m} / \mathrm{z}$ 191 and 179 and 135 . The weak signal (5\% of base peak) of the ion at $\mathrm{m} / z 173$ could indicate the absence of a $\mathrm{C} 4$ substituent.

Various signals at $\mathrm{m} / \mathrm{z} 337$ were detected in C. monogyna (peaks 5, 6, 8 and 9) and $S$. nigra (peaks 2, 5 and 6) samples. These compounds were tentatively identified according to their $\mathrm{MS}^{2}$ fragmentation as different isomers of $p$-coumaroyl quinic acid. Identities were assigned based on the patterns reported for the caffeoylquinic acid isomers. Thus, fragmentation of both peak 5 and 6 (C. monogyna), yielding a majority $\mathrm{MS}^{2}$ product ion at $m / z 173$ was coherent with 4-O-p-coumaroylquinic acid. Peak 6 with higher areas was associated to the trans isomer, whereas the much smaller peak 5 with similar mass spectral characteristics was assigned to cis 4-O-p-coumaroylquinic acid. This assumption was supported in the analysis of the Crataegus sample after UV irradiation. In this case, contrary to what happened for peak 2 , the irradiation led to a decrease in the area of peak 6 and a concomitant increase in that of peak 5 suggesting inter-conversion and supporting their trans/cis nature. As above indicated, the $p$ coumaric moiety seemed to be more sensible to isomerization than caffeic acid. It should also be noted that in our HPLC chromatograms the cis isomer elutes before the corresponding trans, contrary to what was reported by Clifford et al. $(2003,2006)$ in 
samples of cider and Aster ageratoides. The particular HPLC conditions used by Clifford's and the closer retention times between both isomers may explain this difference in the HPLC elution order.

Peaks 9 (C. monogyna) and 6 (S. nigra) were identified as trans 5-O-p-coumaroylquinic acid due to the base peak at $m / z 191$, accompanied by a weak fragment at $\mathrm{m} / \mathrm{z} 163$ corresponding to $[p \text {-coumaric acid-H] }]^{-}$Peaks 8 in $C$. monogyna and 5 in $S$. nigra with UV spectra and $\mathrm{MS}^{2}$ fragmentation patterns and abundances identical to that of the usual trans 5-O-p-coumaroylquinic (peak 9 in $C$. monogyna and peak 6 in S. nigra) were tentatively identified as the corresponding cis isomers.

\subsection{Flavonols}

Flavonols were the main flavonoids found in all the studied samples, being quercetin derivatives ( $\lambda_{\max }$ around $354 \mathrm{~nm}$, and $\mathrm{MS}^{2}$ fragment at $\left.\mathrm{m} / \mathrm{z} 301\right)$, particularly abundant. Quercetin-3-O-rutinoside was found in all the studied medicinal flowers, while quercetin-3-O-glucoside was only found in C. monogyna and S. nigra samples. Both compounds were positively identified according to their retention, mass and UV-vis characteristics by comparison with commercial standards. Other detected quercetin glycosides were peak 14 in C. monogyna, peaks 1 and 2 in C. multiflorus and peak 7 in S. nigra, which were respectively assigned to a quercetin acetyl hexoside ([M-H $]^{-}$at $\mathrm{m} / \mathrm{z}$ 505), peaks $1\left([\mathrm{M}-\mathrm{H}]^{-}\right.$at $\left.\mathrm{m} / \mathrm{z} 505\right)$, quercetin dihexoside $\left([\mathrm{M}-\mathrm{H}]^{-}\right.$at $\left.\mathrm{m} / \mathrm{z} 625\right)$, quercetin acetyl dihexoside $\left([\mathrm{M}-\mathrm{H}]^{-}\right.$at $m / z$ 667), and quercetin hexoside (pseudomolecular ion $[\mathrm{M}-\mathrm{H}]^{-}$at $m / z 463$ ), according to their pseudomolecular ions and $\mathrm{MS}^{2}$ spectra, releasing fragments corresponding to the losses of hexosyl moieties (-162 amu) and, in the respective cases, the acetyl residue (-42 amu). In none of them the identity of the sugar and positions of location of the substituents could be established. 
Kaempferol derivatives ( $\lambda_{\max }$ around $346 \mathrm{~nm}$, and $\mathrm{MS}^{2}$ fragment at $m / z 285$ ) were also found in all the samples, being kaempferol-3-O-rutinoside present in all the analysed flowers but $C$. multiflorus. Another undefined kaempferol hexoside was found in this latter sample (peak 7) as well as in M. sylvestris (peak 6), for which the nature of the hexosyl residue could not be established. A kaempferol acetyl hexoside was also detected in C. multiflorus (peak 8) releasing $\mathrm{MS}^{2}$ fragments at $m / z 327$ ([M-162]', loss of a hexose moiety) and at $m / z 285$ ([M-42]', loss of an acetyl moiety).

Another group of detected flavonols were isorhamnetin derivatives according to their $\mathrm{UV}$-vis and mass spectra (all of them released an $\mathrm{MS}^{2}$ product ion at $\mathrm{m} / \mathrm{z} 315$ ); they were found in C. monogyna (peak 17), M. sylvestris (peak 8) and S. nigra (peak 12). The two latter peaks were positively identified as isorhamnetin-3-O-rutinoside and isorhamnetin-3-O-glucoside by comparison with standards, whilst peak 17 in $C$. monogyna was assigned to an undefined isorhamnetin acetylhexoside from the loss of 204 amu (-162-42 amu, corresponding to hexosyl + acetyl residues).

Finally, laricitrin and syringetin derivatives were tentatively in $M$. sylvestris sample, presenting UV spectra with $\lambda_{\max }$ at $354 \mathrm{~nm}$, and showing pseudomolecular ions $[\mathrm{M}-\mathrm{H}]^{-}$ at $m / z 639$ and 653, respectively, each of them releasing a unique $\mathrm{MS}^{2}$ fragment at $\mathrm{m} / \mathrm{z}$ 331 (laricitrin) and 345 (syringetin), respectively. The loss of -308 amu in both peaks was coherent with the presence of a rutinoside moiety.

\subsection{Flavones}

Flavones were also found in all the medicinal flowers, with exception of $S$. nigra. The main flavones found were $C$-glycosylated, as revealed from their fragmentation pattern different to that of the $O$-glycosides (Ferreres et al., 2003; Ferreres et al., 2004; Ferreres et al., 2007; Barros et al., 2011c; Barros et al., 2011d; Ferreres et al., 2011). Different 
peaks could be associated to apigenin derivatives according to their UV and mass spectral characteristics. Peak 10 in C. monogyna showed a pseudomolecular ion [M-H] at $m / z 577$, releasing five $\mathrm{MS}^{2}$ fragments ions. The loss of -120 amu (ion at $m / z 457$ ([M-120] $]^{-}$is characteristic of $C$-hexosyl flavones (Ferreres et al., 2003), whereas the loss of $164 \mathrm{amu}$, leading to the fragment at $m / z 413$ ([M-146-18] $\left.]^{-}\right)$is characteristic of an $O$-glycosylation on the hydroxyl group at position 2 of the $C$-glycosylation sugar (Ferreres et al., 2007). The other three ions at $\mathrm{m} / \mathrm{z} 341$ ([aglycone+71)], $\mathrm{m} / \mathrm{z} 311$

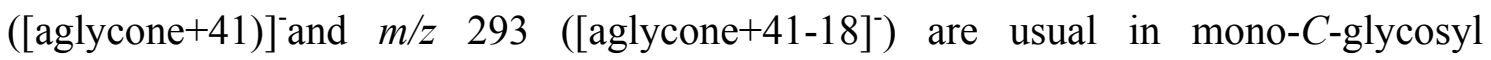
derivatives $O$-glycosylated on 2"' position (Ferreres et al., 2007). Thus, this peak could be tentatively identified as 2 '- $O$-rhamnose- $C$-hexoside apigenin. This assumption was also supported by the observations of Ferreres et al. $(2007,2011)$ that found similar fragmentation patterns and abundances for $O$-glycosyl- $C$-glycosyl flavones with $O$ glycosylation on the phenolic hydroxyl or on the $C$-glycosyl residue or combination of both forms. Similar reasoning was applied for the assignment of peak $16\left([\mathrm{M}-\mathrm{H}]^{-}\right.$at $\mathrm{m} / \mathrm{z}$ 619) in C. monogyna as an acetyl derivative of peak 10, as both of them presented similar fragmentation pattern and UV spectra with the difference that peak 16 was 42 amu (acetyl residue) greater than peak 10.

Peaks 4 and 5 in C. multiflorus presented pseudomolecular ions [M-H]- at $m / z 579$ and 563, respectively, that yielded $\mathrm{MS}^{2}$ fragment ions at $m / z 459$ and 443, ([M-120]-, characteristic of $C$-hexoxyl flavones), and $m / z 429$ and 413 ([M-150]') from the loss of $150 \mathrm{amu}(132+18)$, typical of a pentosyl moiety from $O$-glycosylation in a phenolic hydroxyl group. Other three fragment ions released from both peaks corresponded to $[\text { aglycone }+71]^{-},{ }^{2}$ aglycone +41$]^{-}$and $[\text {aglycone }+41-18]^{-}$associated to mono- $C$-glycosyl derivatives $O$-glycosylated on 2 "' position, which allowed identifying them as 2 "'-Opentosyl-8-C-hexosides of luteolin and apigenin, respectively. The fragmentation 
pattern and relative abundance of fragments indicated sugar substitution at $C-8$ according to Ferreres et al. $(2007,2011)$.

Peak 11 in $M$. sylvestris was identified as apigenin 7-O-glucoside, according to its retention, UV spectrum and mass characteristics compared with an authentic standard. Peaks 12 in the same sample presented similar UV spectra with $\lambda_{\max }$ around $336 \mathrm{~nm}$ and the same pseudomolecular ion $[\mathrm{M}-\mathrm{H}]^{-}$at $m / z 431$ as peak $11 . \mathrm{MS}^{2}$ yielded two fragment ions at $m / z 311$ (loss of $120 \mathrm{amu}$, characteristic of $C$-hexosyl flavones), and at $\mathrm{m} / z 269$ (-162 amu, loss of an hexosyl moiety). The loss of 120 amu but not 90 amu suggested that the sugar was located at position $8-C$, and thus the compound was identified as apigenin 8 - $C$-hexoside.

Peaks $9\left([\mathrm{M}-\mathrm{H}]^{-}\right.$at $\mathrm{m} / \mathrm{z}$ 877) and $10\left([\mathrm{M}-\mathrm{H}]^{-}\right.$at $\mathrm{m} / z$ 973) in $C$. multiflorus showed identical UV spectra with $\lambda_{\max }$ at $268-280 \mathrm{~nm}$, and their parent ions released a major $\mathrm{MS}^{2}$ fragment at $\mathrm{m} / \mathrm{z}$ 253, which allowed tentatively assigning them as chrysin derivatives, although they could not be fully identified.

The $\mathrm{MS}^{2}$ analysis of peak 9 yielded five fragments at $\mathrm{m} / \mathrm{z} 831$ [M-46]', (loss of formic acid), $m / z 669$ [M-46-162]', (loss of formic acid and hexoside moiety). The successive losses of the formic acid molecule and sugar moiety could point out that the sugar linked to chrysin, could be esterified with formic acid. The other three fragments at $\mathrm{m} / \mathrm{z}$ 461, 415 and 253 presented the same fragmentation pattern; the loss of $208 \mathrm{amu}$ (46+162), which suggested the loss of two hexosides moieties and formic acid molecules, leading to an tentatively suggestion that the second hydroxyl group of the aglycone could be linked to disaccharide that could be esterified with two formic acid molecules. Peak 10 has a similar fragmentation pattern to peak 9, also having a similar chemical structure to this compound, it was identified as a chrysin derivative, but no more conclusions could be taken in the identification of this peak. 


\subsection{Procyanidins}

A peak that could correspond to a procyanidin trimer (peak 7) was also detected in the C. monogyna sample. This identity was assigned based on its a UV spectrum, with $\lambda_{\max }$ at $280 \mathrm{~nm}$, and pseudomolecular ion [M-H] ${ }^{-}$at $m / z 865$.

\section{Concluding remarks}

As far as we know, there is no information on the phenolic composition of $M$. sylvestris flowers, although previous studies have been published dealing M. sylvestris leaves (Nawwar and Buddrust, 1981; Billeter et al., 1991). Otherwise, for C. monogyna and $S$. nigra flowers there are a few publications on their phenolic composition but from other countries, such as France (Froehlicher et al., 2009) for C. monogyna, Austria (Rieger et al., 2008), Denmark (Christensen et al., 2008; Kaack and Christensen, 2010) and Poland (Dawidowicz et al., 2003) for S. nigra. Froehlicher et al. (2009) only described the most abundant phenolic compounds present in C. monogyna flowers, being phenolic acids (chlorogenic and caffeic acids), and some flavonoids such as epicatechin and quercetin3-O-galactoside the majority compounds found. In the present study up to 17 compounds have been identified, including some of those previously reported, but also other flavonols, flavones and chlorogenic and $p$-coumaric acid derivatives.

For $S$. nigra, all the previous studies reported the presence of quercetin-3-O-glucoside (isoquercitrin) and quercetin-3-O-rutinoside (rutin), as well as different caffeoylquinic acids, as also observed in the present study (Christensen et al., 2008; Rieger et al. 2008). In a sample analysed by Kaack and Christensen (2008) not only quercetin but also other flavonols (kaempferol-3-O-rutinoside isorhamnetin acetylhexoside) were detected as for the Portuguese sample here studied. 
Regarding C.multiflorus flowers, there is a recent report on the phenolic composition in cultivated samples (Pereira et al., 2012), which showed some similarities with the herein studied wild flowers, such as the presence of flavone- $C$-glycosides and flavonols, namely quercetin derivatives, although the variety of flavones and flavonols detected in our study was greater.

Overall, the present study represents a contribution to the chemical characterization of phenolic extracts from wild flowers with reported antioxidant activity and traditionally used for several medicinal applications.

\section{Acknowledgements}

L. Barros thanks to FCT, POPH-QREN and FSE for her grant (SFRH/BPD/4609/2008). M. Dueñas thanks to the Programa Ramón y Cajal for a contract. The GIP-USAL is financially supported by the Spanish Ministerio de Ciencia e Innovación through the Consolider-Ingenio 2010 Programme (FUN-C-FOOD, CSD2007-00063), and Junta de Castilla y León (Grupo de Investigación de Excelencia, GR133).

\section{References}

Barros, L., Cabrita, L., Vilas-Boas, M., Carvalho, A.M., Ferreira, I.C.F.R. 2011a. Chemical, biochemical and electrochemical assays to evaluate phytochemicals and antioxidant activity of wild plants. Food Chem. 127, 1600-1608.

Barros, L., Carvalho, A.M., Ferreira, I.C.F.R. 2011b. Comparing the composition and bioactivity of Crataegus monogyna flowers and fruits used in folk medicine. Phytochem. Anal. 22, 181-188. 
Barros, L., Dueñas, M., Días, I., Sousa, M.J., Santos-Buelga, C., Ferreira, I.C.F.R., 2011c. Phenolic profiles of in vivo and in vitro grown Coriandrum sativum. Food Chem. 132, 841-848

Barros, L., Dueñas, M., Ferreira, I.C.F.R., Carvalho, A.M., Santos-Buelga, C. 2011d. Use of HPLC-DAD-ESI/MS to profile phenolic compounds in edible wild greens from Portugal. Food Chem. 127, 169-173.

Barros, L., Carvalho, A.M., Ferreira, I.C.F.R. 2010. Leaves, flowers, immature fruits and leafy flowered stems of Malva sylvestris: A comparative study of the nutraceutical potential and composition. Food Chem. Toxi. 48, 1466-1472.

Billeter, M., Meier B., Sticher, O. 1991. 8-Hydroxyflavonoid glucuronides from Malva sylvestris. Phytochem. 30, 987-990.

Castroviejo, S. (coord.). 2001, 2005, 2007. Flora Iberica. Plantas vasculares de la Península Ibérica e Islas Baleares. Real Jardín Botánico, CSIC, Madrid.

Carvalho, A.M. 2010. Plantas y sabiduría popular del Parque Natural de Montesinho. Un estudio etnobotánico en Portugal, CSIC, Biblioteca de Ciencias $\mathrm{n}^{\mathrm{o}} 35$, Madrid.

Christensen, L.P., Kaack K., Frette X.C. 2008. Selection of elderberry (Sambucus nigra L.) genotypes best suited for the preparation of elderflower extracts rich in flavonoids and phenolic acids. Eur. Food Res. Technol. 227, 293-305.

Clifford, M.N., Johnston, K.L., Knight, S., Kuhnert, N.A. 2003. A hierarachical scheme for $\mathrm{LC}_{-\mathrm{MS}}^{\mathrm{n}}$ identification of chlorogenic acids. J Agric. Food Chem. 51, 29002911.

Clifford, M.N., Knight, S., Kuhnert, N.A. 2005. Discriminating between the six isomers of dicaffeoylquinic acid by LC-MS ${ }^{\mathrm{n}}$. J Agric. Food Chem. 53, 3821-3832. 
Clifford, M.N., Knight, S., Kuhnert, N.A. 2006. Profiling the chlorogenic acids of Aster by HPLC-MS ${ }^{\mathrm{n}}$. Phytochem. Anal. 517, 384-393.

Clifford, M.N., Wu, W., Kirkpatrick, J., Kuhnert, N.A. 2007. Profiling the chlorogenic acids and other caffeic acid derivatives of herbal chrysanthemum by HPLC$\mathrm{MS}^{\mathrm{n}}$. J Agric. Food Chem. 55, 929-936.

Dawidowicz, A.L., Wianowska, D., Gawdzik, J., Smolarz, D.H. 2003. Optimization of ASE conditions for the HPLC determination of rutin and isoquercitrin in Sambucus nigra L. Liq. Chromatogr. Relat. Technol. 26, 2381-2397.

Eliel, E.L., Ramirez, M.B. 1997. (-)-Quinic acid: configurational (stereochemical) descriptors. Tetrahedron: Asymmetry 8, 3551-3554.

Fecka, I. 2009. Qualitative and quantitative determination of hydrolysable tannins and other polyphenols in herbal products from meadowsweet and dog rose. Phytochem. Anal. 20, 177-190.

Ferreres, F., Silva, B.M., Andrade, P.B., Seabra, R.M., Ferreira, M.A. 2003. Approach to the study of $C$-glycosyl flavones by ion trap HPLC-PAD-ESI/MS/MS: application to seeds of quince (Cydonia oblonga). Phytochem. Anal. 14, 352359.

Ferreres, F., Gil-Izquierdo, A., Andrade, P.B., Valentao, P., Tomás-Barberán, F.A. 2007. Characterization of $C$-glycosyl flavones $O$-glycosylated by liquid chromatography-tandem mass spectrometry. J Chromatog. A 1161, 214-223.

Ferreres, F., Gil-Izquierdo, Vinholes, J., Grosso, C. Valentão, P., Andrade, P.B. 2011. Approach to the study of $C$-glycosyl flavones acylated with aliphatic and aromatic acids form Spergularia rubra by high-performance liquid 
chromatography-photodiode array detection/electrospray ionization multi-stage mass spectrometry. Rap. Comm. Mass Spec. 25, 700-712.

Froehlicher, T., Hennebelle, T., Martin-Nizard, F., Cleenewerck, P., Hilbert, J.-L., Trotin, F., Grec, S. 2009. Phenolic profiles and antioxidative effects of hawthorn cell suspensions, fresh fruits, and medicinal dried parts. Food Chem. $115,897-903$.

Ghafourifar, P., Cadenas, E. 2006. Mitochondrial nitric oxide synthase. Trends in Pharmacol. Sci. 26, 190-195.

Halliwell, B., Gutteridge, J.M.C. 1999. Free radicals in biology and medicine (3rd Ed.). Oxford University Press, Oxford, UK.

He, F.J., Nowson, C.A., MacGregor, G.A. 2006. Fruit and vegetable consumption and stroke: metaanalysis of cohort studies. Lancet, 367, 320-326.

IUPAC. Nomenclature of cyclitols. Biochem.J. 1976; 153: 23-31.

Kaack, K., Christensen, L.P. 2010. Phenolic acids and flavonoids in tea processed from flowers of black elder (Sambucus nigra L.) stored in different packing materials. Eur. J. Horticult. Sci. 75, S-214-220.

Lin L.Z, Harnly J.M. 2008. Identification of hydroxycinnamoylquinic acids of arnica flowers and burdock roots using a standardized LC-DAD-ESI/MS profiling method. J. Agric. Food Chem. 56, 10105-10114.

López-Lázaro, M. 2002. Flavonoids as anticancer agents: Structure-activity relationship study. Curr. Med. Chem. Anti-Can. Agent. 2, 691-714.

Nawwar, M.A.M., Buddrus, J. 1981. A gossypetin glucuronide sulphate from the leaves of Malva sylvestris. Phytochemistry, 20, 2446-2448. 
Pereira, O.R., Silva, A.M.S., Domingues, M.R.M., Cardoso, S.M. 2012. Identification of phenolic constituents of Cytisus multiflorus. Food Chem. 131, 652-659.

Rechner A.R., Kuhnle G., Bremner P., Hubbard G.P., Moore K.P., Rice-Evans C.A. (2002). The metabolic fate of dietary polyphenols in humans. Free Radical Biology and Medicine, 33, 220-235.

Rieger, G., Muller, M., Guttenberg, H., Bucar, F. 2008. Influence of altitudinal variation on the content of phenolic compounds in wild populations of Calluna vulgaris, Sambucus nigra, and Vaccinium myrtillus. J. Agric. Food Chem. 56, 90809086.

Steinberg, F.M, Bearden, M.M., Keen, C.L. 2003. Cocoa and chocolate flavonoids: Implications for cardiovascular health. J American Diet Assoc. 103, 215-223.

Valko, M., Leibfritz, D., Moncol, J., Cronin, M.T., Mazur, M., Telser, J. 2007. Free radicals and antioxidants in normal physiological functions and human disease. Int J Biochem Cell Biol. 39, 44-84.

Youdim, K.A., Spencer, J.P.E., Schroeter, H., Rice-Evans, C. 2002. Dietary flavonoids as potential neuroprotectants. Biol. Chem. 383, 503-519. 
Table 1. Medicinal uses of flowers from these medicinal species reported in some European ethnobotanical surveys (Carvalho, 2010; Barros et al., 2010; Barros et al., 2011a; Barros et al., 2011b).

\begin{tabular}{|c|c|c|c|c|c|}
\hline Species & English name & Local name & Preparations & Therapeutics & Country \\
\hline Crataegus monogyna Jacq & Common hawthorn & $\begin{array}{l}\text { Espinheiro, } \\
\text { escaramunheiro }\end{array}$ & Infusion, gargles & $\begin{array}{l}\text { Cardiovascular disease, } \\
\text { atherosclerosis, arthritis, } \\
\text { and hypertension, } \\
\text { respiratory system } \\
\text { affections, tranquilizer, } \\
\text { obesity and menopause } \\
\text { disturbances }\end{array}$ & $\begin{array}{l}\text { Portugal, Albania, } \\
\text { Bulgaria, France, Italy, } \\
\text { Spain }\end{array}$ \\
\hline Cytisus multiflorus L. & White Spanish broom & Giesta branca & Infusion, decoction & $\begin{array}{l}\text { Metabolic and endocrine } \\
\text { system disorders, } \\
\text { hypertension, rheumatism } \\
\text { and headache. Panacea }\end{array}$ & Portugal \\
\hline Malva sylvestris $\mathrm{L}$. & Common mallow & Malva & $\begin{array}{l}\text { Decoctions, baths, } \\
\text { gargles, lotions, vapour } \\
\text { baths, syrups }\end{array}$ & $\begin{array}{l}\text { Acne, skin condition and } \\
\text { injuries, eyes, throat pain, } \\
\text { cough, stomachic, mild } \\
\text { laxative. Panacea }\end{array}$ & $\begin{array}{l}\text { Portugal, Albania, } \\
\text { Bulgaria, France, Italy, } \\
\text { Spain }\end{array}$ \\
\hline Sambucus nigra L. & Elder & Sabugueiro & $\begin{array}{l}\text { Infusion, poultices, } \\
\text { ointments }\end{array}$ & $\begin{array}{l}\text { Respiratory system } \\
\text { affections, skin injuries, } \\
\text { wounds diabetes, blood } \\
\text { cleanser, stomachic, } \\
\text { diuretic. Panacea }\end{array}$ & $\begin{array}{l}\text { Portugal, Albania, } \\
\text { Bulgaria, France, Italy, } \\
\text { Spain }\end{array}$ \\
\hline
\end{tabular}


Table 2. Retention time (Rt), wavelengths of maximum absorption in the visible region $\left(\lambda_{\max }\right)$, mass spectral data, relative abundances of fragment ions, tentative identification and quantification of the phenolic compounds in the studied medicinal flowers.

\begin{tabular}{|c|c|c|c|c|c|c|}
\hline Peak & $\begin{array}{l}\text { Rt } \\
(\min )\end{array}$ & $\begin{array}{l}\lambda_{\max } \\
(\mathrm{nm})\end{array}$ & $\begin{array}{l}\text { Molecular ion } \\
{[\mathrm{M}-\mathrm{H}]^{-}(\mathrm{m} / \mathrm{z})}\end{array}$ & $\begin{array}{l}\mathrm{MS}^{2} \\
(m / z)\end{array}$ & Tentative identification & $\begin{array}{l}\text { Quantification } \\
(\mathrm{mg} / \mathrm{g}, \mathrm{dw})\end{array}$ \\
\hline \multicolumn{7}{|c|}{ Crataegus monogyna } \\
\hline 1 & 7.1 & 326 & 353 & 191(100),179(84),173(7),135(55) & cis 3-O-Caffeoylquinic acid & $0.02 \pm 0.00$ \\
\hline 2 & 8.7 & 328 & 353 & 191(100),179(63),173(11),135(74) & trans 3-O-Caffeoylquinic acid & $0.16 \pm 0.02$ \\
\hline 3 & 10.2 & 326 & 353 & 191(49),179(70),173(100),135(61) & 4- $O$-Caffeoylquinic acid & $0.21 \pm 0.01$ \\
\hline 4 & 10.7 & 326 & 353 & 191(100),179(23),173(25),135(18) & 5-O-Caffeoylquinic acid & $2.33 \pm 0.10$ \\
\hline 5 & 11.4 & 312 & 337 & $191(19), 173(100), 163(24), 155(4), 137(7)$ & cis 4-O-p-Coumaroylquinic acid & $0.22 \pm 0.01$ \\
\hline 6 & 12.5 & 312 & 337 & $191(6), 173(100), 163(70), 155(16), 137(23)$ & trans 4-O-p-Coumaroylquinic acid & $1.44 \pm 0.08$ \\
\hline 7 & 13.2 & 280 & 865 & $451(44), 425(59), 407(97), 289(65)$ & Procyanidin trimer & $1.38 \pm 0.01$ \\
\hline 8 & 13.4 & 312 & 337 & 191(100),173(23),163(15),155(3),137(2) & cis 5-O-p-Coumaroylquinic acid & $0.39 \pm 0.00$ \\
\hline 9 & 13.6 & 312 & 337 & $191(100), 173(25), 163(15), 155(3), 137(2)$ & trans 5-O-p-Coumaroylquinic acid & $0.22 \pm 0.02$ \\
\hline 10 & 15.0 & 339 & 577 & 457(16),413(100),341(6), 311(23),293(91) & 2"'-O-Rhamnose- $C$-hexoside apigenin & $0.75 \pm 0.00$ \\
\hline 11 & 15.6 & 354 & 609 & $301(100)$ & Quercetin 3-O-rutinoside & $0.88 \pm 0.01$ \\
\hline 12 & 16.2 & 354 & 463 & $301(100)$ & Quercetin 3-O-glucoside & $4.66 \pm 0.27$ \\
\hline 13 & 16.9 & 346 & 593 & $285(100)$ & Kaempferol-3- $O$-rutinoside & $0.64 \pm 0.03$ \\
\hline 14 & 17.1 & 354 & 505 & 463(9),301(63) & Quercetin acetyl hexoside & $0.45 \pm 0.01$ \\
\hline 15 & 17.3 & 328 & 515 & $353(100), 191(81), 179(57), 173(5), 135(29)$ & 3,5-Di- $O$-caffeoylquinic acid & $0.55 \pm 0.04$ \\
\hline 16 & 18.1 & 340 & 619 & $499(12), 457(2), 413(100), 341(3), 311(15), 293(91)$ & 2"'-O-Rhamnose- $C$-acetyl-hexoside apigenin & $2.00 \pm 0.04$ \\
\hline 17 & 18.3 & 336 & 519 & $315(100)$ & Isorhamnetin acetylhexoside & $0.82 \pm 0.03$ \\
\hline \multicolumn{7}{|c|}{ Cytisus multiflorus } \\
\hline 1 & 11.3 & 354 & 625 & $463(100), 301(50)$ & Quercetin dihexoside & $0.43 \pm 0.05$ \\
\hline 2 & 13.3 & 354 & 667 & $505(62), 463(75), 301(50)$ & Quercetin acetyldihexoside & $0.14 \pm 0.02$ \\
\hline
\end{tabular}




\begin{tabular}{|c|c|c|c|c|c|c|}
\hline 3 & 14.0 & 348 & 693 & $459(41), 429(100), 357(34), 327(81), 309(34)$ & Luteolin derivative & $1.72 \pm 0.03$ \\
\hline 4 & 14.2 & 348 & 579 & $459(23), 429(73), 357(71), 327(100), 309(66)$ & 2"'-O-Pentoxide-8-C-hexoside luteolin & $2.31 \pm 0.01$ \\
\hline 5 & 15.1 & 336 & 563 & 443(4),413(100),323(2),311(9),293(84) & 2"'-O-Pentoxide- 8 - $C$-hexoside apigenin & $2.40 \pm 0.02$ \\
\hline 6 & 15.6 & 354 & 609 & $301(100)$ & Quercetin-3-O-rutinoside & $4.06 \pm 0.34$ \\
\hline 7 & 16.5 & 346 & 447 & $285(100)$ & Kaempferol hexoside & $5.74 \pm 0.70$ \\
\hline 8 & 18.5 & 346 & 489 & $489(100), 327(1), 285(61)$ & Kaempferol acetylhexoside & $2.61 \pm 0.25$ \\
\hline 9 & 23.5 & $268,308 \mathrm{sh}$ & 877 & $831(9), 669(12), 461(42), 415(10), 253(100)$ & Chrysin derivative & $12.82 \pm 0.11$ \\
\hline 10 & 25.8 & $270,306 \mathrm{sh}$ & 973 & $669(3), 598(18), 461(28), 339(32), 253(100)$ & Chrysin derivative & $22.29 \pm 0.05$ \\
\hline \multicolumn{7}{|c|}{ Malva sylvestris } \\
\hline 1 & 12.1 & 328 & 353 & 191(27),179(13),173(44),135(6) & Caffeoylquinic acid & $0.15 \pm 0.01$ \\
\hline 2 & 13.3 & 328 & 179 & $135(100)$ & Caffeic acid & $0.63 \pm 0.01$ \\
\hline 3 & 14.4 & $292,334 \mathrm{sh}$ & 463 & $301(100)$ & Hesperetin hexoside & $0.25 \pm 0.02$ \\
\hline 4 & 15.6 & 354 & 609 & $301(100)$ & Quercetin-3-O-rutinoside & $0.20 \pm 0.00$ \\
\hline 5 & 15.8 & 354 & 639 & $331(100)$ & Laricitrin rutinoside & $0.09 \pm 0.01$ \\
\hline 6 & 16.4 & 345 & 447 & $285(100)$ & Kaempferol hexoside & $0.31 \pm 0.02$ \\
\hline 7 & 16.9 & 346 & 593 & $285(100)$ & Kaempferol-3-O-rutinoside & $0.84 \pm 0.03$ \\
\hline 8 & 17.2 & 348 & 623 & $315(100)$ & Isorhamnetin rutinoside & $0.05 \pm 0.00$ \\
\hline 9 & 17.4 & 354 & 653 & $345(100)$ & Syringetin rutinoside & $0.07 \pm 0.01$ \\
\hline 10 & 17.9 & 350 & 447 & 447(100), 285(49) & Kaempferol-3- $O$-glucoside & $0.12 \pm 0.00$ \\
\hline 11 & 18.6 & 337 & 431 & 431(100), 269(65) & Apigenin-7-O-glucoside & $0.26 \pm 0.02$ \\
\hline 12 & 18.9 & 336 & 431 & 431(100), 311(17),269(13) & Apigenin-8- $C$-hexoside & $0.87 \pm 0.01$ \\
\hline \multicolumn{7}{|c|}{ Sambucus nigra } \\
\hline 1 & 7.2 & 326 & 353 & 191(100),179(82),173(8),135(68) & cis 3-O-Caffeoylquinic acid & $0.23 \pm 0.03$ \\
\hline 2 & 9.4 & 312 & 337 & 191(20),173(12),163(100),155(6) & 3-O-p-Coumaroylquinic acid & $0.15 \pm 0.01$ \\
\hline 3 & 10.7 & 326 & 353 & 191(100),179(8),173(10),135(4) & 5-O-Caffeoylquinic acid & $3.38 \pm 0.05$ \\
\hline 4 & 12.0 & 326 & 353 & 191(100) & Caffeoylquinic acid & $0.03 \pm 0.00$ \\
\hline 5 & 13.4 & 312 & 337 & 191(100),173(10),163(4) & cis 5-O-p-Coumaroylquinic acid & $0.33 \pm 0.02$ \\
\hline
\end{tabular}




\begin{tabular}{lllllll}
6 & 13.8 & 312 & 337 & $191(100), 173(4), 163(6)$ & trans 5-O-p-Coumaroylquinic acid & $0.23 \pm 0.01$ \\
7 & 14.9 & 354 & 463 & $301(100)$ & Quercetin hexoside & $0.07 \pm 0.00$ \\
8 & 15.6 & 354 & 609 & $301(100)$ & Quercetin 3-O-rutinoside & $14.93 \pm 0.18$ \\
9 & 16.3 & 354 & 463 & $301(100)$ & Quercetin 3- $O$-glucoside & $2.39 \pm 0.02$ \\
10 & 16.9 & 346 & 593 & $285(100)$ & Kaempferol 3-O-rutinoside & $1.57 \pm 0.07$ \\
11 & 17.3 & 330 & 515 & $353(100), 191(54), 179(44), 173(4), 135(15)$ & 3,5 -Di- $O$-caffeoylquinic acid & $1.06 \pm 0.17$ \\
12 & 18.1 & 354 & 477 & $315(100)$ & Isorhamnetin 3-O-glucoside & $1.58 \pm 0.03$ \\
\hline
\end{tabular}




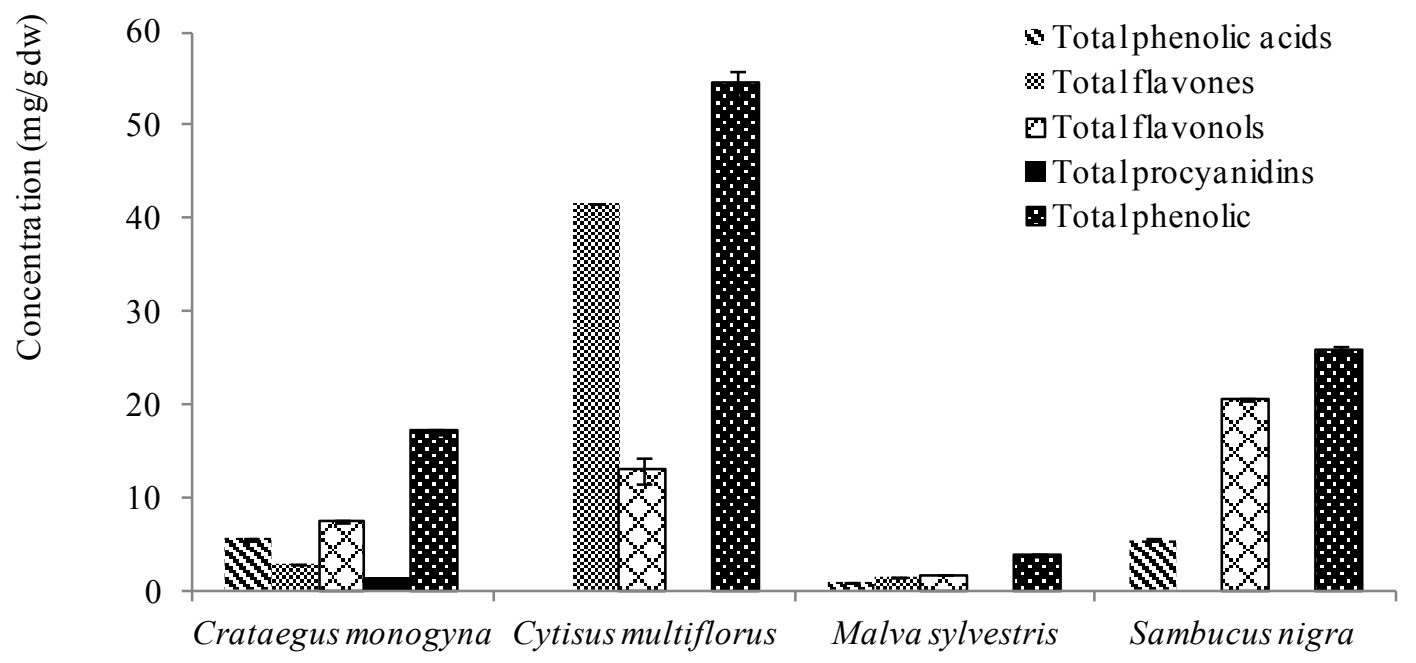

Figure 1. Concentrations of the different classes of phenolic compounds found in the studied wild flowers. 

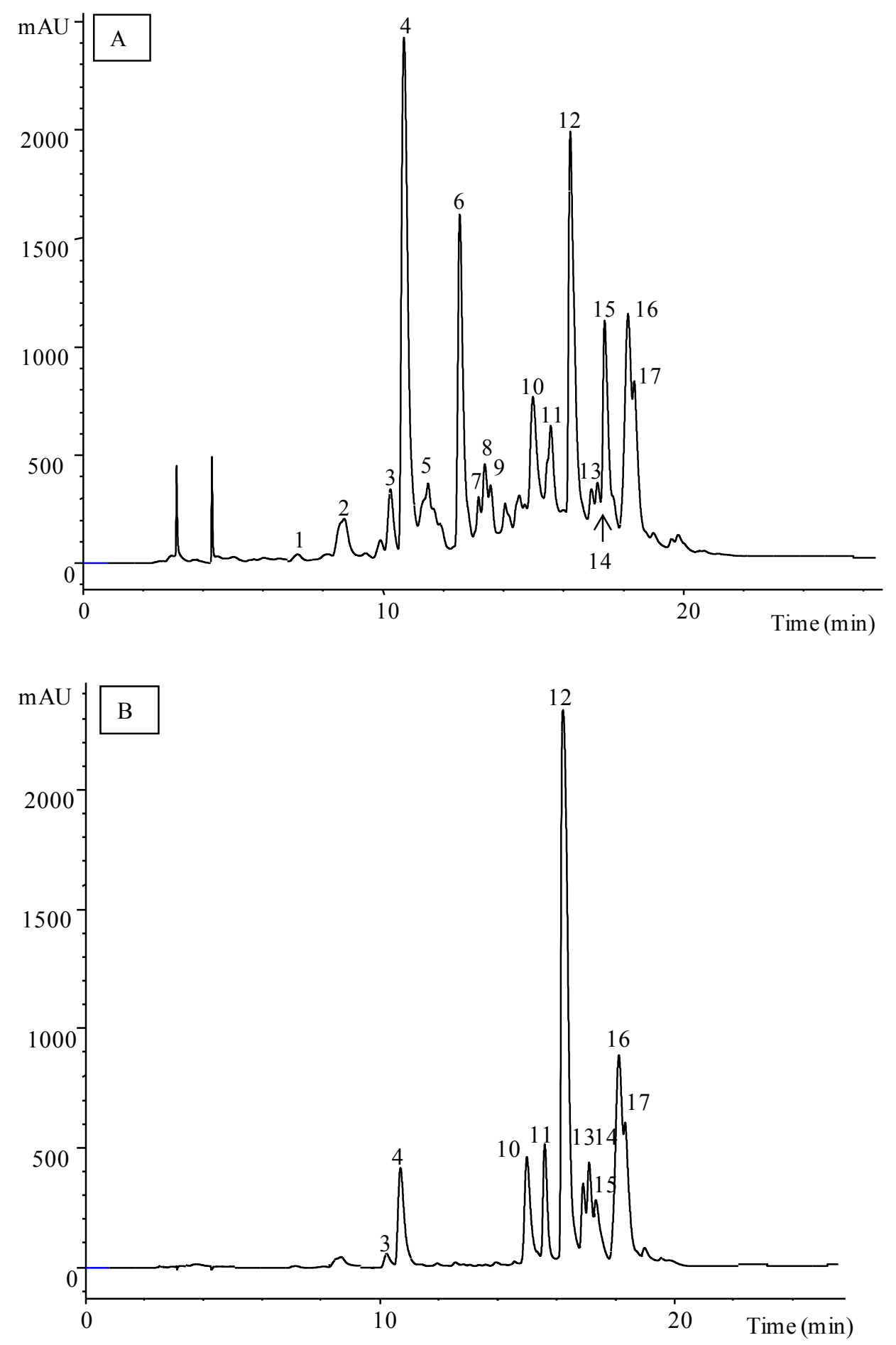

Figure 2. HPLC chromatogram of the phenolic extract of Crataegus monogyna flowers recorded at $280 \mathrm{~nm}(\mathrm{~A})$ and $370 \mathrm{~nm}(\mathrm{~B})$. 
<smiles>O=C(O)/C=C/c1ccc(O)c(O)c1</smiles>

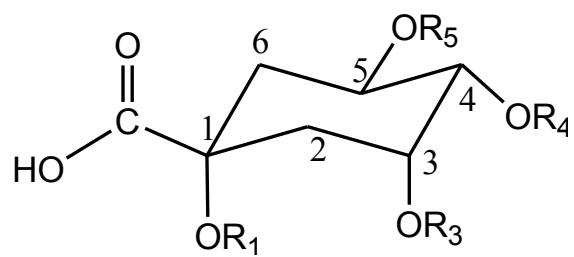<smiles>O=C(O)/C=C/c1ccc(O)cc1</smiles>

1-O-Caffeoylquinic acid, $\mathrm{R}_{1}=$ caffeoyl, $\mathrm{R}_{3}=\mathrm{R}_{4}=\mathrm{R}_{5}=\mathrm{OH}$

3-O-Caffeoylquinic acid, $\mathrm{R}_{3}=$ caffeoyl, $\mathrm{R}_{1}=\mathrm{R}_{4}=\mathrm{R}_{5}=\mathrm{OH}$

4-O-Caffeoylquinic acid, $\mathrm{R}_{4}=$ caffeoyl, $\mathrm{R}_{1}=\mathrm{R}_{3}=\mathrm{R}_{5}=\mathrm{OH}$

5-O-Caffeoylquinic acid, $\mathrm{R}_{5}=$ caffeoyl, $\mathrm{R}_{1}=\mathrm{R}_{3}=\mathrm{R}_{4}=\mathrm{OH}$

3,5-Di-O-caffeoylquinic acid, $\mathrm{R}_{3}=\mathrm{R}_{5}=$ caffeoyl, $\mathrm{R}_{1}=\mathrm{R}_{4}=\mathrm{OH}$

3-O-p-Coumaroylquinic acid, $\mathrm{R}_{3}=p$-coumaroyl, $\mathrm{R}_{1}=\mathrm{R}_{4}=\mathrm{R}_{5}=\mathrm{OH}$

4-O-p-Coumaroylquinic acid, $\mathrm{R}_{4}=p$-coumaroyl, $\mathrm{R}_{1}=\mathrm{R}_{3}=\mathrm{R}_{5}=\mathrm{OH}$

5-O-p-Coumaroylquinic acid, $\mathrm{R}_{5}=p$-coumaroyl, $\mathrm{R}_{1}=\mathrm{R}_{3}=\mathrm{R}_{4}=\mathrm{OH}$

Figure 3. Structures of the different caffeoylquinic acids and coumaroylquinic acids identified in the studied wild flowers (IUPAC numbering) (IUPAC, 1976). 